\title{
UMA PERSPECTIVA COMPARATIVA DA GESTÃO DE
PROJETOS DE EDIFICAÇÕES NO BRASIL E NA FRANÇA
}

\section{Silvio MELHADO}

Engenheiro Civil, Livre-Docente em Tecnologia de Processos Construtivos, Professor Associado da Escola Politécnica da Universidade de São Paulo silvio.melhado@poli.usp.br

\section{Thérèse EVETTE}

Economista, Doutora em Sociologia - Responsável Científica da Rede de Pesquisa RAMAU (Réseau Activités et Métiers de l'Architecture et de

I'Urbanisme) e Professora da École d'architecture de Paris-La Villette

tevette@paris-lavillette.archi.fr

\section{Eric HENRY}

Engenheiro Civil, Sociólogo - Coordenador de pesquisa do Centre de recherche "Innovation Socio-technique et Organisations" e Professor da Université Pierre Mendès France

eric.henry@upmf-grenoble.fr

\author{
Márcio FABRICIO \\ Engenheiro Civil, Mestre em Arquitetura, Doutor \\ em Engenharia Civil, Professor da Escola de \\ Engenharia de São Carlos da Universidade de São \\ Paulo-marcio@sc.usp.br
}

\section{Francisco SEGNINI Jr.}

Arquiteto e Urbanista, Doutor em Arquitetura, Professor da Faculdade de Arquitetura e Urbanismo da Universidade de São Paulo chicosegnini@uol.com.br

\section{François LAUTIER}

Licenciado em Filosofia e em Sociologia, Doutor em Sociologia, Professor da Ecole d'architecture de Paris-La Villette

francois.lautier@paris-lavillette.archi.fr

\section{RESUMO}

A gestão de projetos, bem como a resolução dos conflitos entre os diversos agentes ocorrem de maneiras diferentes, segundo o contexto e as condições particulares de cada país, o que se demonstra a partir das particularidades da trajetória do desenvolvimento do setor da construção, da constituição das profissões e da cultura construtiva. Ainda assim, mesmo sendo sensivelmente diferentes os aspectos históricos, de mercado, a regulamentação e a organização dos empreendimentos e de seus agentes, constatam-se pontos em comum entre o Brasil e a França.

Na França, nos grandes empreendimentos públicos e privados, o papel do empreendedor continua a ser forte, ainda que a programação e o projeto das obras sejam cada vez mais complexos. Em contrapartida, nos empreendimentos corriqueiros a situação não é a ideal e o empreendedor comum tem dificuldades, ainda mais que o número de agentes especializados que a construção exige está crescendo, trazendo interfaces adicionais para a sua gestão. Quanto aos arquitetos, pode-se observar uma forte tendência de ruptura entre o seu trabalho e a gestão dos canteiros de obras. No setor privado, seu papel é freqüentemente restrito ao estudo preliminar e ao projeto legal, visando à aprovação do projeto.

No Brasil, como na Europa, as empresas incorporadoras e construtoras atualmente se vêem diante do desafio da integração de fortes exigências de desempenho e ambientais em seus empreendimentos. Quais serão os impactos para os agentes da construção de edifícios quanto à demanda de competências de projeto e de gestão, exigências contratuais e métodos de acompanhamento das obras?

Este artigo se propõe a abrir a discussão em torno das questões da evolução da gestão de projetos de edificações, assim como das atividades dos profissionais de projeto e de construção nos dois países, contribuindo para uma melhor compreensão das diferenças e semelhanças entre as práticas brasileiras e francesas.

Palavras-chaves: arquitetura, edificações, processo de projeto, coordenação de projetos, gestão de projetos 


\section{ABSTRACT}

Design management practices, as well as the resolution of the conflicts between project players are differently performed according to the context and the particular conditions of each country, from the peculiarities of the trajectory of the construction development, of the professions constitution and of the construction culture. Nevertheless, even being clearly different the historical, market and regulatory aspects as well as the project and construction players structure, it is possible to identify common points between Brazil and France.

In France, in the great public and private projects, the project owner role remains strong, even if project planning and design become more and more complex. On the other hand, in ordinary projects there is not an ideal structure and its project owner is in trouble, even more than the demanded number of specialized construction players is still growing, thus bringing additional interfaces to project management.

It is possible to observe a strong tendency of split-up between architectural design and site works management. In the private sector, architect's role is frequently limited to the preliminary design and to the legal approval of building projects.

Nowadays, in Brazil as in Europe, real estate and construction firms are facing up to the challenge of taking into consideration strong environmental and performance demands in their building projects. Which impacts there will be for the construction players in terms of required design and management competences, contractual exigencies and methods for site works coordination?

This paper intends to open a discussion on the evolution of the building design management, as well as on the activities of design and management professionals in these two countries, aiming to contribute to a better understanding of the differences and similarities between the Brazilian and French practices.

Keywords: architecture, building construction, design coordination, design management

\section{RÉSUMÉ}

Le management des projets de construction, ainsi que la résolution des conflits entre les différents acteurs se passent de manière variée selon le contexte et les conditions particulières de chaque pays. L'histoire du développement du secteur de la construction, la constitution des professions et les cultures constructives particulières en témoignent. Alors que l'histoire, le marché, l'organisation de projet et des acteurs ainsi que la réglementation diffèrent ainsi sensiblement entre la France et le Brésil, on constate aussi des points communs entre les deux pays.

En France, la maîtrise d'ouvrage reste forte dans des secteurs publics ou privés importants, même si la programmation et la conception des ouvrages se sont complexifiés. En revanche, dans les projets courants la situation française n'est pas idéale et la maîtrise d'ouvrage peut être en difficulté de faire sa gestion, de plus que le nombre d'acteurs spécialisés qu'un projet de bâtiment exige est en hausse, ce qui complexifie encore davantage la situation. De la part de l'architecte, on peut observer une forte tendance de coupure entre la maîtrise d'œuvre et les chantiers. Dans le privé son rôle est souvent restraint à l'esquisse et l'avant-projet sommaire pour déposer un permis de construire.

Les promoteurs et entrepreneurs brésiliens amorcent aujourd'hui un changement car ils ont ou auront le défis d'intégrer, comme en Europe, de fortes exigences de performance et environnementales dans leurs programmes. Quels en sont les impacts sur les compétences de conception, l'organisation des projets, la supervision des travaux et les relations contractuelles entre les acteurs des processus de production de l'architecture?

Cet article a pour but de faire une analyse des nouvelles perspectives dans les activités de conception et de construction ainsi que dans les activités des professionnels brésiliens et français de la construction aux deux pays, ce que devrait ouvrir de nouvelles pistes de connaissance sur les différences et les similarités entre les pratiques brésiliennes et françaises.

Mots-clés: architecture, bâtiment, processus de conception, maîtrise d'œuvre, management de la conception 


\section{INTRODUÇÃO}

Várias pesquisas já realizadas, na França assim como no Brasil, se propuseram a analisar e discutir a gestão de projetos de edificações, sob os pontos de vista da qualidade, dos métodos e esquemas organizacionais, das negociações e conflitos entre os principais agentes do empreendimento, das estratégias de ação dos profissionais de projeto, entre outros.

Os empreendimentos de construção de edifícios são cada vez mais complexos e exigem a participação de um número crescente de especialistas, caracterizando equipes de projeto amplas e multidisciplinares. Em conseqüência, aumentaram as demandas de gestão qualificada internamente aos contratantes e os também projetistas foram induzidos a mudanças organizacionais como resposta às novas e mais amplas exigências; a gestão e coordenação dos processos e a colaboração entre os agentes cresceram em importância para que se atinjam os objetivos dos empreendimentos.

Face às dificuldades encontradas e em busca de soluções para melhorar o desempenho dos processos de gestão, surgiram proposições de formas de cooperação antecipada entre o empreendedor e a coordenação de projetos e projetistas, ou entre a coordenação de projetos e projetistas e a execução das obras.

Por outro lado, os profissionais de projeto, enquanto grupos sociais, reagem a essas transformações setoriais e, assim como outros agentes, procuram preservar seus valores. Se por um lado, eles dependem da existência de clientes, pois somente a partir do cliente as edificações adquirem condições de realização, por outro lado, a relação entre projetista e cliente é marcada por conflitos, o mesmo ocorrendo na relação entre os profissionais de projeto e os profissionais responsáveis pela execução de seus projetos.

Assim é que, em meio às evoluções tecnológicas e produtivas que ocorrem na construção de edificações, em que a competição é cada vez mais acirrada, a noção de "qualidade do projeto" é interpretada diferentemente pelos diversos envolvidos no processo, e com freqüência os profissionais de projeto, arquitetos ou engenheiros, sentem-se desvalorizados e até mesmo incompreendidos.

Portanto, são várias as possibilidades que se apresentam para o tratamento dos múltiplos aspectos no processo de projeto de edificações e em sua gestão. Aqui, a proposta se delineia pela oportunidade de se de compararem as práticas de gestão e coordenação de projetos em dois países diferentes, um deles muito estruturado nos aspectos técnicos e regulamentares, portador de seculares tradições no campo da arquitetura e o outro, pouco estruturado, francamente flexível e ao mesmo tempo plenamente competitivo e inovador nos métodos e soluções adotados.

Cabe salientar que este artigo é fruto de uma reflexão preliminar produzida por pesquisadores brasileiros e franceses, com o intuito de estruturar uma série de trabalhos de pesquisa que trarão respostas a algumas questões que, por ora, o texto se propõe a apenas ressaltar. Sua principal contribuição, portanto, situa-se no nível da forma de abordagem e da formulação de questões sobre o futuro próximo das atividades de gestão de projetos de edificações nos dois países, assim criando condições para continuamente aprofundar o tema. 


\section{A RENOVAÇÃO DO SETOR DA CONSTRUÇÃO DE EDIFÍcIOS NO CONTEXTO FRANCÊS}

\subsection{Transformações empresariais e profissionais}

Se o setor da construção de edifícios conservou, por muito tempo, culturas e práticas antiquadas (corporações, pequenas empresas, relações de trabalho e relações profissionais pouco estruturadas), os movimentos que nele atualmente ocorrem são semelhantes aos que são vistos em outros setores de atividade econômica. Enquanto que a construção foi por muito tempo amparada por um paradigma de tradição e de previsibilidade, hoje ela se caracteriza cada vez mais profundamente pela renovação e pela reatividade. As empresas do setor, que eram em geral determinavam suas próprias diretrizes, estão cada vez mais dependentes de fatores externos, ligados ao mercado, aos investidores, aos clientes, ao ambiente, ou mesmo à sociedade em geral.

As empresas e os profissionais se confrontam com a necessidade de se organizarem por projetos, o que demanda competência para atuar em contextos incertos, de reagir rapidamente, sob a pressão dos riscos e dos prazos, desenvolvendo e revendo estratégias. Isso tudo supõe uma forte capacidade de iniciativa e de assumir responsabilidade por parte dos indivíduos e das organizações.

Ao mesmo tempo, uma tendência forte leva as empresas a se libertarem das atividades-meio e a se concentrarem em suas melhores competências para se manterem competitivas. A terceirização de atividades tornou-se uma das formas quase impostas de gestão. Criaram-se novas relações de trabalho, fundamentadas em relações diretas e indiretas, com a presença de diversas formas de parceria, de subcontratação e de desenvolvimento conjunto.

Pode-se dizer que se trata de uma lógica baseada na confiança, capaz de proteger e estabilizar relações comerciais e entre profissionais, que não elimina as hierarquias e o emprego da autoridade, mas confere uma maior importância às relações pessoais e às formas de cooperação.

Estas transformações são apoiadas pelo desenvolvimento dos sistemas técnicos, que continuam a evoluir e a mostrar novos resultados potenciais. A tecnologia da informação e os novos recursos de comunicação intervêm nas relações entre indivíduos e grupos, modificando as atividades e as formas de organização. Algumas novas especialidades profissionais surgem, outras conhecem profundas mutações, outras desaparecem.

De tudo que foi dito até aqui, é importante sublinhar aquilo que é comum a todos os sistemas de produção da atualidade: a necessidade de adaptações às permanentes mutações das atividades, o que fragiliza e acelera a obsolescência dos referenciais técnicos e processuais, derrubando as soluções e as formas de avaliação convencionais. Os desafios do presente exigem mais a flexibilidade do que a especificidade, a competência do que a qualificação, a negociação do que a hierarquia.

\subsection{O surgimento de novos processos na produção de edificações}

Os empreendedores estão sujeitos a incertezas cada dia mais fortes, relativas à concepção dos seus produtos imobiliários. O tratamento das questões ambientais, 
a compressão de prazos dos processos e das obras, a interdependência entre agentes, a solução de conflitos tecnologia - função, as exigências de uso, operação e manutenção, a inserção no meio urbano são alguns dos aspectos complexos das mudanças setoriais. A reabilitação de edificações surge para impulsionar ainda mais essa renovação da problemática da construção.

Nos processos, as formas de intervenção se multiplicam, com um número crescente de trocas e necessidade de acordos envolvendo cada vez mais agentes. As tomadas de decisão são coletivas e as cadeias produtivas mais longas; os projetos alteram-se freqüentemente em função do progresso do trabalho de outros processos do empreendimento; cada indivíduo vê confrontado o seu saber especializado com conhecimentos mais globais.

$\mathrm{Na}$ França, a política de renovação urbana exige processos complexos de intervenção da parte dos agentes da construção e amplia as dimensões fundiárias, econômicas, sociais e espaciais envolvidas. $\mathrm{O}$ mesmo vale para os empreendimentos de infra-estrutura viária e projetos industriais nos quais a sociedade civil também intervém. É também o caso de empreendimentos mais corriqueiros que se inserem no tecido urbano, que lhes impõe fortes restrições.

Essa situação leva a instituir a negociação como elemento-chave nas relações entre os parceiros. Assim, ganham destaque os processos de coordenação e torna-se estratégico o papel da gestão de projetos dentro de um contexto instituído de complexidade.

\subsection{A fusão de campos de atuação profissional e a criação de novas competências}

Atualmente, dentro das funções de concepção, desenvolvimento e detalhamento, fica clara a enorme diversidade de profissionais que intervêm no processo de projeto, demonstrando uma forte divisão de tarefas e de responsabilidades. Por exemplo, para um empreendimento residencial simples, caberá ao promotor a definição do produto imobiliário. Aos arquitetos, a concepção do projeto e seu desenvolvimento, em vários estágios, do estudo preliminar ao projeto detalhado. Aos engenheiros de projeto e consultores, as soluções técnicas e o detalhamento da produção. Ao economista da construção1, o controle dos custos do empreendimento. Poder-se-ia detalhar mais ainda estas grandes atividades e explodi-las em elementos de missões profissionais, como de fato o faz a lei francesa sobre gestão de obras públicas (concepção do projeto, do estudo preliminar ao detalhamento, contratação das obras, supervisão e coordenação da execução, etc.).

Do mesmo modo, seria possível demonstrar-se essa diversidade apresentando-se as especialidades ou disciplinas mobilizadas, que se multiplicam com a evolução das regulamentações e das exigências impostas aos empreendimentos: a segurança, a acústica, a iluminação, o meio ambiente, a energia, etc. A fragmentação assume formas diferentes de acordo com o tipo de empreendimento ou forma de contratação que se considere (residencial/construções comerciais/industriais/infra-estrutura, contratação pública/contratação privada), trazendo um contexto cuja importância está em identificar de modo específico a

\footnotetext{
${ }^{1} \mathrm{Na}$ França, existe instituída uma especialidade profissional denominada Economista (da construção), que não é convencional no Brasil ou, ao menos, não é exercida como tal, separadamente de outras especialidades profissionais.
} 
dinâmica das atividades e das relações entre agentes, e suas formas de engajamento.

A principal legitimidade dos profissionais de projeto reside na individualização das suas relações com os seus clientes e na clareza do seu papel de prestador de serviços externo em relação a eles. Na França, no setor da construção pública, tentou-se delimitar claramente o que é da competência do empreendedor (programação de necessidades, definição do investimento, tomada de decisões) e o que deve ser responsabilidade dos profissionais de coordenação de projetos, no plano da concepção arquitetônica, técnica e construtiva. Mas esta delimitação é cada vez menos estanque e os papéis de uns e de outros se sobrepõem cada vez com mais freqüência. Os mesmos profissionais podem se encontrar em posição de assessorar a fase inicial do empreendimento e, em seguida, serem contratados como projetistas com diversas atribuições, o que a regulamentação francesa havia pretendido evitar. Os empreendedores, por sua vez, freqüentemente realizam internamente uma parte ou um complemento das atribuições que confiam aos seus projetistas contratados.

Durante muito tempo, pensava-se que a coordenação de projetos se estruturava essencialmente pela intersecção entre uma função e uma profissão institucionalizada. A competência atestada por um diploma impunha a autoridade do profissional dentro dessa área de atuação. Ora, na verdade, as fronteiras da atuação profissional se deslocam com a evolução dos produtos, das formas de contratação, e também com a dinâmica própria de evolução dos grupos profissionais dentro do setor da construção. Enquanto ocorrem trocas de papéis entre empreendedores e profissionais de projeto, os diferentes grupos profissionais adotam estratégias de especialização e de diversificação. Essas mudanças parecem buscar um equilíbrio, às vezes contraditório, entre a definição de uma competência essencial das profissões e a agregação de novas especialidades técnicas ou de gestão. De fato, os espaços profissionais tradicionais no setor da construção são modificados e se produz a adaptação ou criação de novas especialidades.

A complexidade dos processos e a fragmentação das missões são acompanhadas por movimentos de recomposição das formas de atuação. Isso pode ser notado a partir das múltiplas formas de parcerias ou de integração que se estabelecem entre os agentes, do lado dos empreendedores como d o lado dos projetistas. Assim, se institui a negociação como forma de relacionamento entre os parceiros.

Paralelamente, acentua-se o caráter estratégico dos processos de gestão e de coordenação de projetos para se gerir a complexidade, que traz desafios em termos de desempenho ao mesmo tempo em que demanda maior controle de etapas e do todo do processo de projeto e de produção dos empreendimentos.

\subsection{Qualidade do projeto na França: definições e pontos de discussão}

Pode-se partir de uma definição genérica de projeto, deixando de lado a visão restritiva que se impôs historicamente no setor da construção, pela força da constituição e da regulamentação das profissões. A definição em questão é a que prevalece na normalização e a literatura científica sobre os processos de criação de produtos inovadores (ECOSIP, 1999). A concepção de um produto inovador é 
entendida como resultado do desenvolvimento simultâneo do produto, das suas funções em uso e do seu processo de produção.

Da mesma forma, é possível pensar que qualquer empreendimento complexo de construção apresente aspectos inovadores e, por isso, deveria aproximar as considerações quanto ao projeto das análises feitas quanto à sua execução e seu uso, operação e manutenção. E também podemos dizer que, por outro ponto de vista, levando-se em conta a ampliação do projeto transversalmente às profissões e especialidades, são questionáveis os métodos adotados no projeto de edificações.

\section{O processo de projeto}

O projeto é um conjunto de atividades intelectuais que levam à concepção das exigências para a construção, das formas e dimensões do produto e de seus métodos construtivos. Pode-se estabelecer, então, com uma visão bem geral e prática, três fases do projeto, sem se prender às denominações usuais no setor:

- Concepção das exigências para a construção (C-CC);

- Concepção do produto (C- PR);

- Concepção da execução das obras (C-EX).

\section{Os pólos de produção dos empreendimentos}

As fases acima polarizam e, juntas, condensam a concepção do empreendimento; elas não têm nem os mesmos objetivos, nem os mesmos recursos e competências, nem os mesmos prazos; elas podem se sobrepor totalmente (projeto simultâneo2) ou parcialmente, duas a duas, em um desenrolar seqüencial, tradicional do processo de produção de empreendimentos ou, mais exatamente, embutindo-se uma na outra e criando tensões e conflitos.

Essas fases, ou subprocessos, são atribuídas aos empreendedores, aos projetistas e aos construtores, e desenvolvidas de modo a se constituírem pólos de produção dos empreendimentos, que vão envolver um certo número de agentes, direta ou indiretamente.

Na França, elas poderiam ser assim atribuídas:

- $\mathrm{C}-\mathrm{CC}=$ Concepção das exigências para a construção - atribuída aos empreendedores e seus consultores (sigla MOA-AMO, do francês maître d'ouvrage et assistants maître d'ouvrage);

- $\quad \mathrm{C}-\mathrm{PR}=$ Concepção do produto - atribuída ao arquiteto e engenheiros de projeto (sigla MOE-BET, do francês maître d'œuvre et bureaux d'études techniques);

- C-EX = Concepção da execução das obras - atribuída às construtoras e aos projetistas especializados(sigla ENT-BET, do francês entreprises et bureaux d'études techniques).

\section{A grande amplitude e dispersão do processo de projeto}

Uma parte muito considerável das atividades de gestão de empreendimentos e de coordenação de projetos, bem como uma porção menor das atividades de execução

\footnotetext{
${ }^{2}$ Conceito derivado da Engenharia Simultânea, praticada em setores da produção industrial seriada, o Projeto Simultâneo foi criado pela transposição dessa prática para o ambiente e condições próprias dos empreendimentos da construção civil (a esse respeito, ver Fabricio, 2002).
} 
deveriam ser, assim, consideradas como atividades integrantes do processo de projeto (C-CC, C- PR, C-EX) com exceção de atividades de contratação, gestão, comunicação ou suprimento relativas à execução propriamente dita das obras.

A construção pode ser analisada como uma atividade de "produção por projetos", ou de "produção por empreendimento" (LE GALL, 1998), do que decorre naturalmente a obrigação de se realizarem estudos específicos e substanciais embora se trate de uma atividade de produção por mão-de-obra não especializada..A título de estimativa (sem tomar por base estudos numéricos a respeito), pode-se afirmar que, para empreendimentos corriqueiros, o conjunto das atividades de planejamento e de projeto representa algo como 15 a $20 \%$ do tempo global de realização do empreendimento e para operações técnica e espacialmente mais complexas pode atingir os $25 \%$.

\section{A qualidade do projeto}

A noção de "qualidade do projeto" parece remeter de modo essencial à qualidade do empreendimento para os usuários atuais e futuros, cujas avaliações devem se alterar ao longo da vida útil da edificação. Por conseguinte, há sempre um pouco de incerteza e de controvérsia quanto ao julgamento que se faz da qualidade dos empreendimentos. A "promessa" de qualidade formulada nas etapas iniciais do processo sempre é acompanhada de imprecisões e riscos, como define Philippe Dehan (DEHAN, 2001). E aqueles que têm a principal responsabilidade, os arquitetos e projetistas de engenharia, na essência, sentem-se freqüentemente "incompreendidos" ou até mesmo "traídos" pelos seus clientes, pelas construtoras e pelos próprios usuários.

Pode-se ainda ir mais longe e evocar as diversas formas de julgamento - financeiro, estético, técnico, funcional e ambiental - que incidem sobre a qualidade do empreendimento, para destacar a importância da qualidade das interfaces entre projetistas e da qualidade da gestão do processo de projeto, inserido no "fogo cruzado" entre os agentes do empreendimento e demais partes interessadas. A obtenção da qualidade do projeto, assim, continuará a ser sempre problemática.

É este quadro que se pretende discutir de um ponto de vista teórico e prático, enfocando as tentativas de evolução do processo de projeto. Inicialmente, serão tratados os princípios que habitualmente regulam a gestão de projetos de edificações.

\section{O modelo seqüencial e suas deficiências}

Os modelos predominantes de organização de empreendimentos e projetos são de caráter hierárquico e seqüencial: na indústria, o modelo de G. Pahl e W. Beitz, denominado modelo da "engenharia", formalizado na Europa e nos Estados Unidos durante os anos 80; na construção francesa, o modelo da lei "MOP" de 1984, que distingue e tende a colocar em oposição os empreendedores (MOA), a coordenação de projeto e projetistas (MOE) e as empresas construtoras. Esse modelo é fundamentado pelo princípio básico de resolução de problemas por soluções previsíveis que não são detalhadas passo a passo em seqüências sucessivas. A ampliação progressiva da escala dos projetos, desde os estudos preliminares até os detalhamentos, no processo de projeto é um exemplo que ilustra bem tal princípio. 
- Este modelo permite estabelecer um controle econômico por uma série de contratos em cascata, contratos negociados e estabelecidos sobre uma base de preço global, ditos "contratos caixa preta" ou "contratos incompletos" (à exceção de certos contratos por tarefa, como obras de fundações e outros serviços);

- Inicialmente, o empreendedor e todos os demais intervenientes sabem disso e procuram se proteger transferindo riscos, na medida do possível, para os seus clientes ou fornecedores. Assim, habitualmente, o empreendedor e o coordenador do projeto buscam uma formalização detalhada e um caráter inalterável dos contratos para se protegerem das ameaças que constituem os interesses divergentes das empresas ou de outras partes envolvidas;

- Porém, certos coordenadores de projetos exigentes e dedicados têm também uma estratégia oposta, que consiste em deixar certa imprecisão nos contratos, criando uma margem de negociação em caso de aumento do escopo de serviço das construtoras. É o que se pode chamar de um "blefe" profissional;

- As construtoras, por sua vez, sem terem acesso ou sem experiência anterior positiva com aqueles profissionais, vêem no contrato a preço global uma fonte de riscos e procuram prevenir-se apresentando propostas superficiais para atendimento às exigências formuladas, com o objetivo muito claro de terem "margem de manobra" no decorrer das obras.

A organização seqüencial é uma modalidade eficaz para atribuir as responsabilidades, proteger o gestor de dinheiro público e distinguir funções e competências, mas do ponto de vista da qualidade do projeto esse modelo apresenta deficiências importantes em todo empreendimento que não seja simples e banal, em que a definição de exigências, a arquitetura, a técnica, os métodos construtivos e as estratégias dos agentes são conhecidos e sem grande risco para todos.

Quais são, mais precisamente, essas deficiências?

- Cada agente é levado a trabalhar sobre o "seu" projeto enquanto que seria melhor trabalhar sobre um projeto comum, uma vez que ele apresente um caráter complexo, quanto ao produto, inovação técnica ou mesmo pelos agentes envolvidos;

- O projeto (C-PR) é visto como uma atividade contratada, da qual o empreendedor e as empresas construtoras são excluídos;

- O cliente que paga considera ter "sempre razão", enquanto é considerado como "leigo" e responsável apenas pela definição de necessidades (C-CC);

- Os arquitetos prescrevem muito bem aquilo que eles conhecem e já experimentaram, mas a separação entre o projeto do produto e as soluções técnicoconstrutivas das obras levam-nos freqüentemente a correrem riscos não considerados;

- A fase de concepção da execução (C-EX) não é considerada realmente como atividade que contribui para o projeto e para a qualidade do empreendimento. Ela fica mascarada, escondida pela transição entre projeto e obra, como um simples anexo da execução, durante a fase de preparação da execução3, cuja função de detalhamento conjunto do projeto a construir não é reconhecida;

\footnotetext{
${ }^{3}$ A preparação da execução de obras é constituída por atividades de transição entre as fases de projeto e de execução, obrigatoriamente realizadas no início da execucão das obras públicas na França, e foi extensamente tratada em uma Tese de Doutorado (SOUZA, 2001).
} 
- A qualidade da edificação, que depende de pesquisa e inovação, são será tão mais dispendiosa quanto for exclusiva de um único empreendimento. Freqüentes desvios de prazos e de custos são especialmente observadas em empreendimentos com projetos "inovadores" ou complexos, muitas vezes presentes no setor público;

- A consideração do conhecimento e da aprendizagem coletiva ligados ao projeto e à gestão de projetos é fraca; constata-se uma falta de instrumentos para projetos colaborativos e sobretudo uma falta de planejamento e de tempo disponível para esta colaboração (HENRY et al., 2000);

- Esse modelo de projeto é puxado por uma reprodução "automática" das concorrências e contratos e é geralmente incapaz de promover e de coordenar empreendimentos e produtos inovadores com eficácia e bom desempenho;

- Dentro do trinômio custo-prazo-qualidade a busca do menor custo de execução das obras é primordial e a referência à contratação pela "melhor técnica" é em geral apenas "fachada".

No entanto, no modelo seqüencial as fases de concepção se conectam, levando a surgirem interstícios ou interfaces de diálogo e de negociação. Duas interfaces em particular constituem dois momentos-chaves no processo de projeto: a articulação e a validação do programa-anteprojeto e, posteriormente, a articulação projetoexecução das obras, que necessitam numerosos detalhamentos técnicos e estudo das múltiplas interfaces entre etapas de execução.

Essas duas interfaces têm uma função de intermediação e de transição essencial para se criar ou tentar manter a qualidade do projeto. Elas se situam na intersecção criada pela mudança de referencial e de linguagem: do esquema funcional à forma arquitetônica e técnica na primeira interface, e da forma arquitetônica e técnica à implementação das obras, na segunda interface.

De uma forma mais ampla, pode-se distinguir claramente:

a) Os interstícios ou momentos de interface organizados no âmbito do processo de projeto: validação Programa/AP; Projeto Detalhado (entre MOA-AMO e MOE$\mathrm{BET}$ ); discussão/aceitação de alternativas (entre MOA-AMO e ENT), nas reuniões em canteiro de obras (entre os três pólos de concepção). Mas a organização de momentos de interface não garante a compreensão mútua, o compartilhamento de pontos de vista e a construção de compromissos com relação à qualidade do projeto; pode simplesmente alimentar negociações sobre questões financeiras ou políticos na interface com o empreendedor, ou ainda negociações relativas aos custos de execução dos serviços, no caso da interface à montante (estando os preços de empreitada já definidos em contrato).

b) As interfaces não institucionalizadas: por exemplo, a empresa construtora sugere modificações que supostamente melhoram a qualidade final da obra, esperando algum tipo de vantagem ou retorno, que pode ser de caráter comercial (esperança de parcerias no futuro), de caráter logístico (maior facilidade no emprego dos seus recursos), de caráter financeiro, no mesmo contrato ou em contrato futuro, ou ainda, de caráter cognitivo (aprendizagem coletiva: a motivação pela evolução conjunta).

O fato de considerar, por princípio, que o projeto se desenvolve como uma seqüência de atividades ao longo de um processo e que o sucesso de um projeto de qualidade passa necessariamente por momentos de compartilhamento, apesar das formas contratuais, permite apenas colocar a tônica sobre a necessidade de se 
estudarem os momentos de diálogo, de confrontação ou de validação entre pólos de concepção. Este diálogo pode melhorar a confiabilidade e a qualidade das soluções de projeto ou apenas conduzir a sucessivas revisões da formulação dos problemas e das soluções para eles propostas (CONAN, 1990).

Dito de outro modo, o sucesso do projeto e a obtenção da qualidade, atendendo a exigências compartilhadas, medir-se-á por um lado à sombra dos métodos de tratamento das interfaces e dos detalhes e, por outro lado, pela capacidade dos agentes de se apreciarem e de se compreenderem, dentro da discussão e interpretação do mérito das propostas apresentadas uns aos outros. De onde se explica a importância habitualmente dada à constituição de uma equipe de projeto coesa em torno de um trabalho em comum, às vezes se estendendo à colaboração e sintonia com a construtora.

Apesar de se poder qualificar a atividade de projeto nas interfaces como uma atividade intersticial, no entanto, ela tem um caráter essencial para a gestão dos projetos. É uma maneira de estabelecer os raros momentos criativos envolvendo colaboração mútua e que balizam o desenrolar de empreendimento.

Em conclusão, no modelo seqüencial, produzido pela forma de contratação habitual de projetos e de obras, os conflitos de interesses, os grandes esforços iniciais, a vontade de trabalhar de forma compartilhada ao longo do processo, parecem-nos necessários, mas nem sempre suficientes para obter a qualidade exigida e desejável. Em suma, seria esperado pelo menos que se desse mais fluidez e regularidade ao processo de projeto, que fossem facilitadas as relações de confiança e a expressão dos pontos de vista dos agentes, capitalizando as proposições e os conhecimentos de todos os envolvidos. Uma expectativa extremamente utópica, se for considerada a estrita aplicação da regulamentação e dos contratos usuais.

\section{A gestão e a certificação da qualidade na França}

Na França, os anos 1997-2000 constituíram uma etapa decisiva para a gestão da qualidade na construção, com a participação do MFQ-BTP (Movimento Francês pela Qualidade na Construção Civil) na revisão das normas ISO 9000, seguida pela sua publicação, que ampliou o envolvimento dos grandes empreendedores públicos e privados, das grandes empresas e dos grandes BET em processos de certificação de suas organizações. Esses processos foram mais exigentes do que a garantia da qualidade (versão antiga da norma) quanto ao compromisso das direções das empresas e mais flexíveis quanto ao formalismo, pois o objetivo principal passou a ser melhorar continuamente o desempenho dos processos, em parceria com os clientes, os fornecedores e demais partes interessadas.

Na mesma época, a Union Sociale pour l'Habitat elaborou, a partir da nova versão das normas ISO 9000, um referencial normativo de qualificação (QUALIMO) para as atividades de maîtrise d'ouvrage dos organismos de habitação de interesse social. Desse modo, na França, pode-se estimar hoje em cerca de cinqüenta o total de empreendedores públicos e privados de porte importante que certificaram ou qualificaram a sua gestão de empreendimentos.

Pesquisas e observações feitas entre 2000 e 2003, com empreendedores e arquitetos certificados de acordo com a ISO 9001 mostraram uma abordagem diferente da gestão do processo de construção, dividindo-o em em subprocessos de 
programação, de projeto e de execução, encadeados entre si, e supervisionados pelo gerente de projeto do empreendedor. A exigência da melhoria contínua levou esses empreendedores a exigir competências dos seus fornecedores, à sua presença nos momentos chave do processo (preparações e validações) e a escutar a voz dos usuários e dos seus parceiros locais. Observou-se que muitos deles utilizaram métodos anteriormente desenvolvidos nos Clubes da Qualidade da Construção franceses.

O processo de certificação da qualidade que, desde o ano 2000, exige da empresa ou organismo uma modelagem dos seus processos (processos de gestão, processos operacionais e processos de apoio), uma abordagem sistêmica, a adoção de relações mutuamente benéficas com os fornecedores e a prática da melhoria contínua é indubitavelmente um vetor de melhoria da qualidade do processo de projeto, estendendo-se aos fornecedores e parceiros. Ela implica contratos aperfeiçoados e validados no início do empreendimento e associados a uma gestão precisa e compartilhada de suas modificações posteriores.

Daí resulta, na prática, uma reconfiguração parcial do processo de projeto e das suas interfaces com os processos operacionais das diversas partes envolvidas, ou seja, uma gestão muito mais rigorosa das interfaces materiais e organizacionais entre os agentes e entre as fases principais dos empreendimentos.

Quando o empreendedor está comprometido, deliberadamente, metódica e permanentemente com a gestão e a certificação da qualidade, a ênfase passa a ser colocada na busca de compromissos positivos durante o projeto e a execução das obras, em lugar da dinâmica de conflitos entre agentes. Observa-se que após alguns anos os MOE e as construtoras tornam-se mais envolvidos nesse processo e na própria aprendizagem do empreendedor de maneira sensível e convincente, até mesmo praticando processos de gestão análogos.

A partir do momento em que adquiriram a mesma linguagem, tornam-se propensos a procurar melhorias para seus processos de projeto e de gestão, como efeito do processo coletivo de aprendizagem. É exatamente a reconfiguração dos processos internos que facilita o desenvolvimento da confiança, do rigor no trabalho e abre caminho para a compreensão mútua entre os parceiros.

Além do processo de certificação da qualidade, é interessante comentar a participação na consultoria e análise dos processos de projeto e de execução do empreendimento Grands Ateliers de l'Isle d'Abeau, conduzidos dentro de princípios de gestão da qualidade (1998-2000). Trata-se de um projeto conjunto de Escolas de Arquitetura, de Engenharia e de Arte e pelo Ministério Francês da Cultura, concebido por um arquiteto da empresa de projeto Lipsky-Rollet. Esse projeto era inovador tanto pela sua função quanto pelos materiais e componentes construtivos a serem produzidos.

A observação cuidadosa e metódica revelou que o projeto desse empreendimento, que agregava qualidade e inovação, passava também por momentos tensos de confrontação e de busca de compromissos positivos quanto às soluções funcionais, estéticas ou técnicas e sua validação. Tais momentos de criação e de colaboração (projeto simultâneo) foram absolutamente necessários à coordenação do projeto. Isso parece ter origem ao mesmo tempo em uma ética dos projetistas e no pragmatismo das relações regulamentares dos agentes da construção na França. 
Esta observação, assim como outras observações anteriores, ilustram o surgimento de um modelo pragmático seqüencial/simultâneo que se origina na busca da qualidade do projeto de edificações.

\section{A busca de um modelo de projeto simultâneo}

O projeto de edificações engloba um vasto campo de atividades e de modelos cognitivos diversificados. A diversidade e a hierarquização seqüencial habitualmente presentes nas atividades de projeto trazem riscos para a obtenção da qualidade do projeto e do empreendimento. Assim, a obtenção da qualidade mostra-se problemática.

Uma gestão do processo de projeto integradora e baseada na compreensão mútua, desde o início da programação até à execução, permite favorecer a obtenção da qualidade mas dificilmente é possível na organização hierárquica e seqüencial tradicional.

Busca-se a criação de modelos de projeto simultâneo, que são difíceis de se imaginar do modo que são encontrados na indústria de produção seriada, ou no caso de produto inovadores na construção; porém, algumas possibilidades surgem, em especial, com a introdução das exigências ambientais para projeto e execução das obras.

É possível imaginar então que à sombra da gestão da qualidade e ambiental novas formas de projeto simultâneo vão facilitar a obtenção da qualidade do projeto. Após a síntese de observações e pesquisas realizadas, podemos concluir que se trata mesmo de um ponto de passagem obrigatório, que favorece o surgimento de um novo modelo de projeto seqüencial-simultâneo.

Nesse novo modelo, três componentes são essenciais:

1. A prioridade para a exploração coletiva, concepção conjunta e validações ao curso das interfaces programação-projeto-execução;

2. A busca de compromissos de projeto ao curso de sessões de trabalho que mobilizem as capacidades subjetivas de compreensão mútua dos profissionais, associada a modelos cognitivos e métodos de trabalho profundamente diferentes;

3. Modalidades de gestão de empreendimentos e de coordenação de projetos que visem principalmente o compromisso e validações sucessivas associadas à busca da eficácia e da racionalização de recursos, caracterizadas pela gestão conjunta do empreendedor e dos projetistas, nas etapas iniciais; e pela gestão conjunta dos projetistas e da construtora nas etapas posteriores do empreendimento.

O empreendedor ocupa uma posição chave entre os usuários finais e os agentes de projeto e de execução de obras; está em suas mãos propor métodos e procedimentos para um trabalho colaborativo que propicie a obtenção da qualidade. 


\section{ANÁlise do CONTEXTO DA GESTÃo DE PROJETOS DE EDIFICAÇÕES NO BRASIL}

\subsection{As diferenças nas práticas de gestão de projetos}

Em relação ao que foi apresentado até agora, é necessário compreender o contexto no qual se situam as semelhanças e as diferenças entre as práticas brasileiras e francesas, e que os agentes principais da construção também apresentam práticas e relações entre si que são diversas.

Desde os anos 70-80, o papel do arquiteto brasileiro foi se reduzindo ao projeto em si, sendo pouco associado ao processo de execução das obras por ele projetadas. Freqüentemente, ele nem mesmo chega mesmo a exercer o direito de verificação de conformidade da obra ao projeto.

A empresa construtora é responsável por um número cada vez maior de atividades com relação aos projetos, além da coordenação da execução e do seu controle. Também impressiona a subcontratação quase total das atividades de execução (pelo menos no contexto de São Paulo), sendo que, freqüentemente, os subempreiteiros não têm o conhecimento técnico e a especialização necessárias, uma vez que a maioria deles é originada de antigos trabalhadores da construção que se tornaram "empresários" quando as construtoras reduziram seus contingentes de mão-de-obra.

Para responder a esse contexto quase "caótico" da construção de edificações, em meados dos anos 90, surgiram as iniciativas de implementação de sistemas de gestão da qualidade, graças às quais as construtoras viveram uma renovação de seus processos e modelos organizacionais. E, alguns anos depois, o Programa Brasileiro de Qualidade e Produtividade tornou compulsória a adoção de sistemas de gestão da qualidade nas empresas.

E, depois da chegada das exigências quanto à gestão da qualidade, a gestão de projetos foi assumida quase totalmente pelas empresas incorporadoras e construtoras. Em conseqüência, surgiu uma nova atividade profissional na qual vários arquitetos se lançaram: a carreira de "coordenador de projetos" dissociada da concepção, seja como funcionários daquelas empresas, seja como seus prestadores de serviços.

Assim, hoje, o processo de projeto se torna cada vez mais estratégico e recebe muito mais atenção que anteriormente. Encontram-se muito mais informações nos desenhos de um projeto e a própria quantidade de pranchas cresceu. Discute-se agora, em alguns casos, sobre a importância da preparação da execução de obras e sobre a retomada da presença em canteiro dos projetistas. Embora as coisas ainda estejam em mutação, com avanços e retrocessos, pode-se afirmar que, de uma certa maneira, as missões "esquecidas" estão sendo novamente demandadas...

Será que o futuro da gestão e coordenação de projetos no Brasil será, de alguma forma, similar ao modelo francês de maîtrise d'ouvrage e maîtrise d'cuvre? Será que o afastamento entre a concepção e a coordenação dos projetos também será rediscutido e modificado na França? 


\subsection{As mudanças nas relações entre os agentes da construção}

No Brasil, até os anos 70-80, ano segmento de edificações, a missão essencial do arquiteto associava a concepção à coordenação de projetos (modelo "clássico"), embora a "coordenação de projetos" nunca tenha sido bem definida em regulamentações profissionais e normas técnicas. Contudo, sucessivas crises econômicas sofridas desde aquela época, com a conseqüente retração de atividades no setor da construção, depreciaram muito a remuneração dos projetos e - ainda que não apenas por esse motivo - os arquitetos afastaram-se dos canteiros de obras.

Assim, os arquitetos perderam muito da sua experiência em gestão de projetos entre e também considerando o envolvimento crescente das empresas incorporadoras e construtoras nessa atividade de gestão, após várias décadas, surgiu um grande afastamento entre concepção arquitetônica e coordenação de projetos. Hoje, é cada vez mais raro que as empresas de projeto de arquitetura estejam capacitadas a coordenarem os projetos, tanto que os contratos não agregam mais esse tipo de prestação de serviços.

Para melhor compreender a situação exposta, a Figura 1 mostra, de maneira simplificada, a organização dos agentes de construção de empreendimentos residenciais do setor privado em São Paulo. Os principais agentes são o empreendedor (o promotor imobiliário), a empresa construtora e os seus subcontratados, bem como os projetistas (arquiteto e engenheiros) responsáveis pelas diferentes especialidades de projeto. Normalmente, existe um engenheiro civil residente para cada canteiro de obras, embora em certos casos um mesmo engenheiro possa ser responsável pela execução de dois ou mais canteiros de obras. Existem igualmente, equipes responsáveis pela gestão da qualidade, pelo planejamento e pelo controle da execução.

Tomando por base a ilustração mostrada na Figura 1, comenta-se a seguir o esquema organizacional básico do processo habitual de gestão de empreendimentos, no contexto da iniciativa privada.

Uma vez tomada a decisão de realizar um empreendimento imobiliário, o empreendedor responsável contrata inicialmente uma empresa de projeto de arquitetura à qual é confiada a concepção inicial. Habitualmente, o empreendedor em questão ainda não contratou, nessa fase, os demais projetistas e a equipe da empresa construtora que será encarregada de executar as obras igualmente não participa ainda do processo. Muitas decisões sobre o projeto serão então tomadas, influenciando a qualidade do projeto.

Um esquema equivalente das relações entre agentes da construção de edificações na França é ilustrado na Figura 2.

Na Figura 3, mostra-se a forma atual de desenvolvimento dos empreendimentos imobiliários do segmento residencial privado. Os pontos em que se apresentam deficiências estão destacados em itálico e em vermelho. 


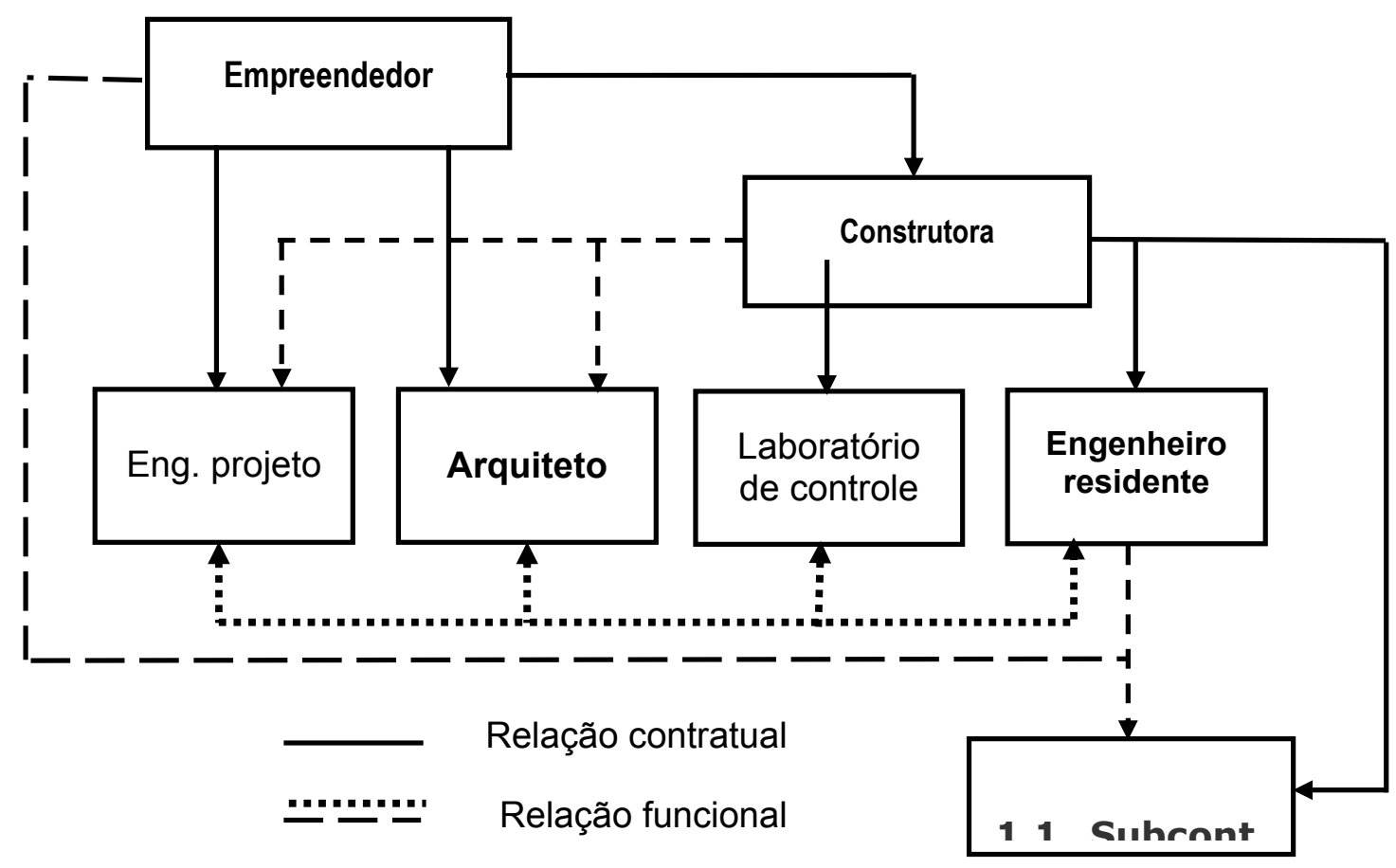

Figura 1: Os agentes principais dos empreendimentos de construção de edificações no Brasil (São Paulo) - adaptado de Souza (2001)

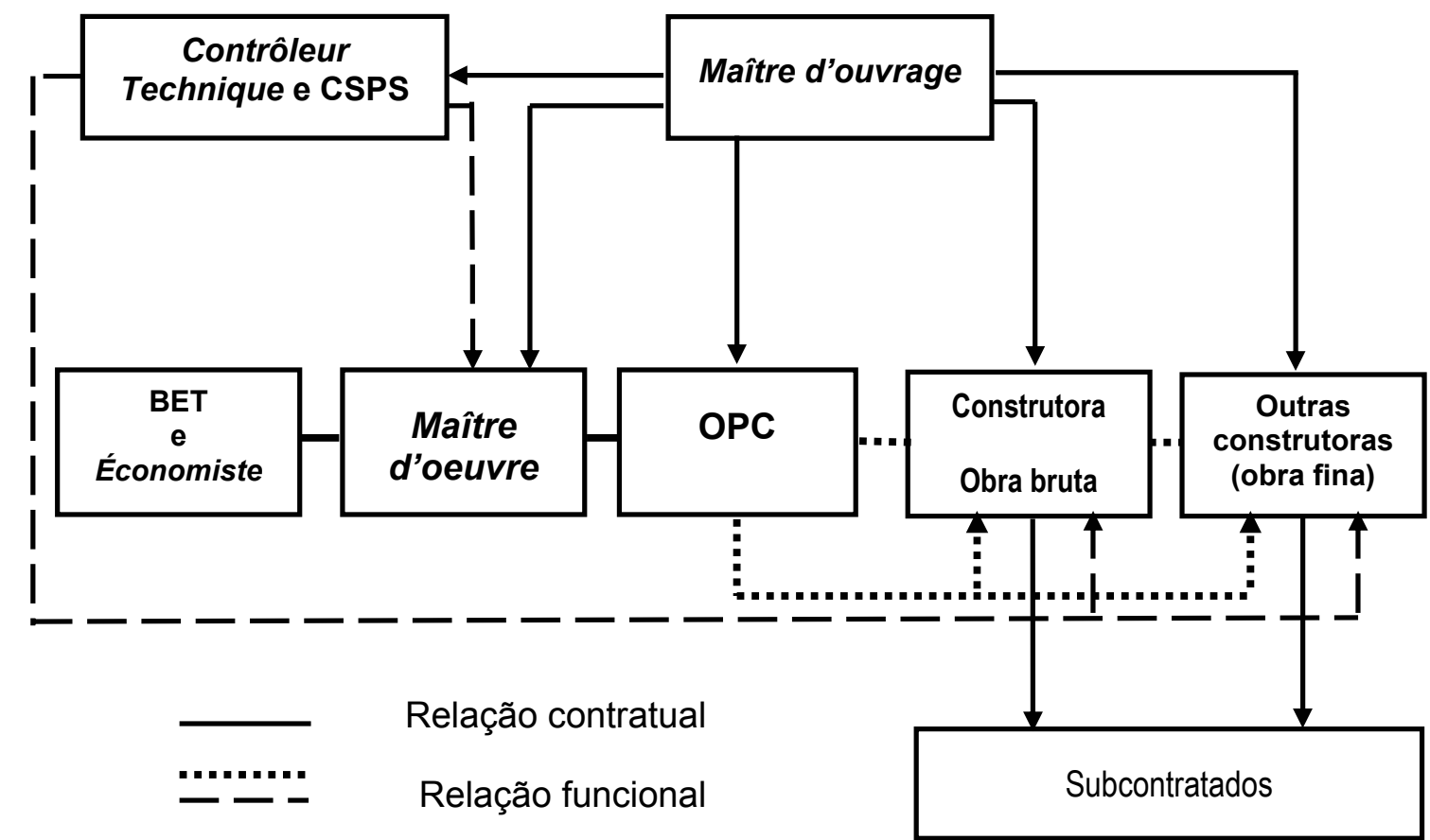

Figura 2: Os agentes principais dos empreendimentos de construção de edificações na França - adaptado de Souza (2001)

Pode-se observar que, no Brasil, "falta" uma última etapa ao processo de projeto. Com efeito, a prestação de serviço do projetista encerra-se com a entrega (por 
vezes, formal e à distância) dos desenhos detalhados do projeto à empresa da construção. Não existe nenhuma regulamentação ou norma que determine que o projetista deva apresentar e discutir seu projeto, no canteiro de obras, com as equipes de execução.

É verdade que certas empresas construtoras estabelecem no contrato dos projetistas exigências específicas que estendem a prestação de serviços da empresa de projeto até à fase de execução; no entanto, mesmo nesses casos, o estímulo é relativo, pois os projetos já terão sido totalmente ou quase totalmente pagos.

É raro observar uma forte interação entre os projetistas e os engenheiros residentes. Os próprios profissionais responsáveis pela coordenação de projeto também não acompanham os projetos que coordenaram, em sua fase de execução, pois habitualmente eles já se encontram comprometidos com os projetos de outros empreendimentos. Tudo isso cria um ciclo vicioso difícil de ser quebrado. Os pretextos para não mudar essa prática são sempre os mesmos: dificuldades ligadas à falta de recursos financeiros nas etapas iniciais dos empreendimentos.

Em resumo, as relações entre empreendedores e profissionais de projeto apresentam dificuldades de ordem comercial e também técnica, sobretudo devido à falta de normas e de regulamentações que possam disciplinar essas relações. Podese dizer que faltam, em especial, referências precisas no que diz respeito ao escopo dos serviços de projeto. Conseqüentemente, há uma tendência a distorções nos contratos de projeto, o que, de um lado, estimula a concorrência por preços sem que seja estabelecida claramente a real prestação de serviço associada a estes preços e, por outro lado, desencadeia conflitos entre clientes e projetistas durante o processo de projeto, o que representa uma perda de qualidade ao mesmo tempo para os processos e para o produto final (empreendimento).

Na Tabela 1, apresentam-se algumas possibilidades de melhoria que podem ser implementadas, em relação às principais falhas identificadas no processo de projeto. 
Empresa incorporadora define o produto e a data para início da execução do empreendimento; contrata o projetista de arquitetura, responsável por desenvolver o projeto do produto e coordenar aspectos relacionados - a empresa construtora e os demais projetistas não interferem nesse momento<smiles>[3H]C[3H]</smiles>

Projetista de arquitetura (coordenador do projeto) desenvolve o anteprojeto e, com a aprovação do incorporador, providencia a aprovação do projeto legal - os projetistas de estruturas e de instalações são consultados, mas ainda não são contratados

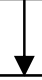

Empresa construtora recebe autorização do incorporador para iniciar a elaboração do projeto pré-executivo - são contratados projetistas de estrutura, de instalações e de vedações (responsável pela compatibilização do projeto) - os demais projetistas se incorporam à equipe posteriormente

Projetistas desenvolvem o projeto executivo sob a supervisão do departamento de projetos da empresa construtora - com rara participação da equipe responsável pela execução da obra (coordenador de obras, engenheiro residente ou subempreiteiros)

Subempreiteiros são contratados pela empresa construtora, dando início à fase de execução de obras - não existe uma fase de transição entre 0 desenvolvimento do projeto e o início da execução da obra dedicada ao estudo, aprimoramento do projeto e planejamento da execução da obra

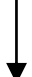

Engenheiro residente, coordenador de obras, técnico de edificações e mestre-deobras estruturam uma equipe de trabalho, com o objetivo de coordenar e controlar a execução e a evolução dos serviços - existe pouco contato com os projetistas e o departamento de projeto da empresa construtora, bem como não é dada ênfase à apresentação do projeto aos subempreiteiros

Usuário final recebe o empreendimento, após conclusão dos serviços - o processo de retroalimentação das decisões tomadas durante a execução da obra é falho; muitas das decisões ficam na "cabeça" dos agentes

Figura 3: Etapas esquemáticas de desenvolvimento de empreendimentos imobiliários em São Paulo (Melhado; Rocha de Souza, 2005) 
Tabela 1: Proposições para melhoria do desempenho do processo de projeto em empresas incorporadoras e construtoras (Melhado, 2001)

\begin{tabular}{|c|c|}
\hline Deficiência identificada & $\begin{array}{l}\text { Orientação proposta para melhoria de } \\
\text { desempenho }\end{array}$ \\
\hline $\begin{array}{l}\text { Projetistas pouco motivados e não-engajados } \\
\text { quanto aos objetivos do cliente }\end{array}$ & $\begin{array}{l}\text { Rever formas de contratação, remuneração e } \\
\text { avaliação das empresas de projeto }\end{array}$ \\
\hline $\begin{array}{l}\text { Coordenadores de obras e engenheiros residentes } \\
\text { participam pouco e tardiamente do processo de } \\
\text { projeto, pois estão envolvidos com obras em } \\
\text { andamento }\end{array}$ & $\begin{array}{l}\text { Priorizar o seu envolvimento nos projetos em fase } \\
\text { inicial e quebrar o círculo vicioso pela substituição } \\
\text { das equipes de obras ligadas a empreendimentos } \\
\text { em fase de término }\end{array}$ \\
\hline $\begin{array}{l}\text { A coordenação de projetos atua de forma pouco } \\
\text { integrada à execução, quase não fazendo visitas às } \\
\text { obras e pouco participando da implementação das } \\
\text { inovações tecnológicas }\end{array}$ & $\begin{array}{l}\text { Racionalizar procedimentos para reduzir o tempo } \\
\text { dispensado ao acompanhamento do processo de } \\
\text { projeto e demais tarefas de escritório, reservando } \\
\text { períodos semanais destinados a visitar as obras } \\
\text { Transferir reuniões finais de detalhamento de } \\
\text { projetos para os escritórios das obras }\end{array}$ \\
\hline $\begin{array}{l}\text { Os projetos são concluídos tardiamente e nem } \\
\text { sempre as informações deles constantes são } \\
\text { efetivamente utilizadas na execução das obras }\end{array}$ & $\begin{array}{l}\text { Definir escopos de projeto claros e rever nível de } \\
\text { detalhamento exigido para os projetos } \\
\text { Vincular planejamento de etapas de projeto ao } \\
\text { planejamento global do empreendimento, de forma } \\
\text { a disponibilizar os projetos em tempo hábil }\end{array}$ \\
\hline $\begin{array}{l}\text { Dificuldades na criação de objetivos em comum } \\
\text { entre gestão da qualidade e gestão da execução das } \\
\text { obras }\end{array}$ & $\begin{array}{l}\text { Transferir parte do sistema de gestão da qualidade } \\
\text { para o nível da gestão das obras, para ampliar } \\
\text { compromissos } \\
\text { Estabelecer prêmios para índices baixos de não- } \\
\text { conformidade, não apenas para cumprimento dos } \\
\text { prazos }\end{array}$ \\
\hline $\begin{array}{l}\text { Integração crítica entre equipes de projeto e de } \\
\text { execução - nem todas as informações são } \\
\text { transferidas, ou adequadamente transferidas }\end{array}$ & $\begin{array}{l}\text { Estabelecer mecanismos para continuidade de } \\
\text { equipes, através da atuação dos coordenadores de } \\
\text { obras, em interface com as equipes de projeto e de } \\
\text { execução }\end{array}$ \\
\hline $\begin{array}{l}\text { Grande número de modificações de projeto, } \\
\text { gerando excesso de registros da qualidade }\end{array}$ & $\begin{array}{l}\text { Rever o processo de projeto e seus pontos para } \\
\text { verificação e controle } \\
\text { Redefinir as saídas de projeto, criando uma fase de } \\
\text { ajuste do projeto no canteiro de obras, envolvendo } \\
\text { as equipes de execução (preparação da execução ) }\end{array}$ \\
\hline
\end{tabular}




\section{CONCLUSÕES}

Na França, as formas de cooperação no segmento de edificações têm uma base histórica e cultural que foi sedimentada progressivamente na prática e constituiu referências para os agentes. Acordos corporativos ou entre grupos de profissionais, contratos e convenções especificam as formas de cooperação em função dos conhecimentos técnicos, econômicos ou sociais específicos, da divisão do trabalho e da segmentação de mercados. Esses acordos coexistem com os conflitos e confrontações e exigem diversos tipos de regulação entre os agentes.

Uma primeira forma de regulação é a regulamentar. Ela especifica mais ou menos os papéis ou mesmo os mercados de atuação de uns e de outros, seja na França, seja em nível europeu. A segunda forma está ligada aos mercados e à posição dominante de certos profissionais ou de certos tipos de empresas em certos segmentos (produtos) ou atividades. A terceira é cultural e formaliza tradições de formas de atuação, visibilidade dos papéis dos agentes, imagens que contribuem para definir posições e expectativas, e estruturas de cooperação.

Decifrar estas formas de regulação entre agentes implica também levar em conta as estratégias das corporações profissionais, sobre as suas negociações com as autoridades públicas, sobre suas atividades de formação de lobby, enfim toda manifestação organizada dos grupos profissionais e os conflitos que entre eles se estabelecem.

No contexto brasileiro, mais especificamente o de São Paulo, a mudança de modelo que está se produzindo na gestão de projetos foi uma resposta necessária ao processo de degradação da imagem do projeto e dos próprios projetistas, que se estendeu durante quase vinte anos e que, hoje, tenta-se corrigir. Procura-se agora recuperar toda a dimensão do projeto, uma atividade de caráter ao mesmo tempo estratégico e operacional, sobre a qual repousam em grande parte os resultados dos empreendimentos, sejam eles medidos em termos da sua rentabilidade financeira, da eficácia dos processos ou da qualidade da obra construída.

Diante dessa nova tomada de consciência do valor do projeto na construção de edificações, surge por parte das empresas mais destacadas uma vontade crescente de redefinir o seu processo de projeto, para assim criar condições favoráveis à uma melhoria contínua, tanto do lado dos empreendedores do setor privado como dos seus projetistas.

Assim, apesar das falhas institucionais e de organização setorial que apresenta o Brasil, particularmente visíveis em pontos como a fraca normalização técnica e a vaga definição dos papéis e das atividades profissionais, a construção de edificações no Brasil evolui na direção de modelos mais eficientes de gestão de projetos.

As ações relativas à atuação profissional e de caráter institucional que começam a surgir no Brasil, bem como as discussões sobre a formação dos arquitetos e de engenheiros de projeto levarão certamente, em médio e longo prazos, a um novo modelo de atuação profissional para os projetistas e para os contratantes de projeto, que condicionam e utilizam os seus serviços, levando uns e outros a reescrever as práticas adotadas até hoje. 


\section{REFERÊNCIAS BIBLIOGRÁFICAS}

CONAN, M. Concevoir un projet d'architecture. Paris, L'Harmattan, 1990. 185p. (Collection Villes et Entreprises)

DEHAN, P. Qualité architecturale et innovation: méthode d'évaluation, Paris: Plan Urbanisme construction, Architecture, Pôle Concevoir, Construire, Habiter, 1999. 21p. (recherche $n^{\circ} 112$ )

ECOSIP. Pilotage et évaluation des processus de conception, sous la direction de J. Perrin. Paris: Ed. L'Harmattan, 1999.

FABRICIO, M. M. Projeto simultâneo na construção de edifícios. Tese (doutorado). São Paulo: Escola Politécnica da Universidade de São Paulo, 2002.

HENRY, E. et al. Rôle, compétences et tâches du mandataire au sein d'une équipe de maîtrise d'œuvre. Grenoble: Club Construction Qualité Isère, 2000. Não publicado.

LE GALL, J. Mémo IQM, Mouvement français pour la qualité. In: Management par projets. 1998. pp.95-112.

MELHADO, S.B. Gestão, cooperação e integração para um novo modelo voltado à qualidade do processo de projeto na construção de edifícios. 235 p. Tese (Livre-docência). São Paulo: Escola Politécnica da Universidade de São Paulo, 2001,

MELHADO S.; ROCHA DE SOUZA A. Qualité et gestion des projets dans le Bâtiment au Brésil : repères sur le domaine des constructions résidentielles privées. Actes des Rencontres RAMAU 2005 - «Qualité et maîtrise des processus dans les projets d'édifices ». 31 mars et $1^{\text {er }}$ avril 2005, Paris - France.

SOUZA, A.L.R. Preparação e coordenação da execução de obras: transposição da experiência francesa para a construção brasileira de edifícios. São Paulo: 2001. 440p. Tese (Doutorado) - Escola Politécnica, Universidade de São Paulo.

\section{BIBLIOGRAFIA CONSULTADA}

ALLUIN, $P$. Ingénieries de conception et ingénieries de production. Paris: PUCA, 1998.

ARNAUD, C. ; FRADIN C.; RYSER J. Maîtrise d'ouvrage publique dans les pays européens. (Grande-Bretagne, Italie, RFA, Suède), Paris: MELATT, 1987.

BEN MAHMOUD-JOUINI, S. Pratiques de projet en co-conception - L'interaction entre la conception du produit et du procès. In: Terrin J.-J. Maîtres d'ouvrage, maîtres d'œuvre et entreprises. Paris: Eyrolles, 2004.

BONNET, M. (resp.) L'élaboration des projets architecturaux et urbains en Europe, Volume 4, Les maîtrises d'ouvrage en Europe: évolutions et tendances. Paris: Plan Urbanisme Construction Architecture, 2000.

BOUTINET, J. P. Anthropologie du projet. Paris: PUF, 1993.

CHADOIN, O.; EVETTE T. (dir.) Activités d'architecte en Europe: nouvelles pratiques. Paris: Éditions de La Villette, Cahiers Ramau 3., 2004.

ESTINGOY, P.; RABATEL M. Maîtrise d'ouvrage publique. Paris: Le Moniteur, 1995.

EVETTE, T. et al. Expertises et savoirs dans la définition des édifices. In: PROST R. (dir.), 2003, Projets architecturaux et urbains. Mutation des savoirs dans la phase amont. Paris: PUCA, 2003. pp. 79-134.

GARCIA, J.P.; GRAND Ph. De la maîtrise d'oeuvre en France: constat et perspectives. Avril 2003. Rapport trouvé dans le site http://www.ramau.archi.fr/ 
HENRY, E. Quality management standardisation in the French construction industry: singularities and internationalisation prospects. Construction Management and Economics, London, (2000).

HENRY, E.; MELHADO S. The difficulties of the public construction procurement in France and main innovative methods proposed for the contractors selection. In: Proceedings of CIB W092 Conference, Procurement systems symposium. Santiago, Chile, 15-19 April 2001.

HENRY, E.; MELHADO S. The French construction industry faced to new ISO 9000 quality certification standards. In: Proceedings of Proceedings of CIB W099 International Conference - International Conference on Implementation of construction quality and related systems : a global update. Lisbon, Portugal, 19-21 June 2000.

LAUTIER, F. (éd.) Les maîtrises d'ouvrage en Europe, évolution et tendances. In: BONNET $M$. (resp.) L'élaboration des projets architecturaux et urbains en Europe, vol. 4. Paris: PUCA, 2000.

MELHADO S.; HENRY E. Quality management in French architectural offices and its singularities. In: Proceedings of CIB w099 International Conference International Conference on Implementation of construction quality and related systems: a global update. Lisbon, Portugal, 19-21 June 2000.

MELHADO, S.B. Linking quality management, teamwork and integration to define a new model of design management for building construction. In: Proceedings of The CIB W99 2003 International Conference - Construction project management systems: The challenge of integration. São Paulo, Brazil, 2003.

TAPIE, G. Les architectes - mutations d'une profession. Paris: L'Harmattan, 2000. (Collection Logiques Sociales)

TERRIN, J. J. Qualité, conception, gestion de projet. Paris: PUCA, 1998. 